\title{
人为气溶胶导致全球陆地季风区降水减少的 动力和热力过程
}

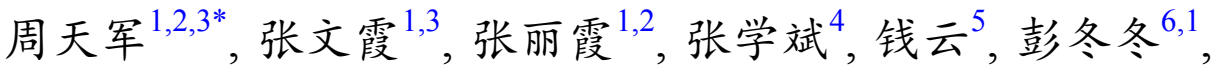 \\ 马双梅 ${ }^{1,3}$, 董步文 ${ }^{7}$
}

1. 中国科学院大气物理研究所大气科学和地球流体力学数值模拟国家重点实验室(LASG), 北京 100029;

2. 中国科学院青藏高原地球科学卓越创新中心, 北京 100101 ;

3. 中国科学院大学, 北京 100049 ;

4. Environment and Climate Change Canada, 4905 Dufferin Street, Toronto, ON, Canada;

5. Atmospheric Science and Global Change Division, Pacific Northwest National Laboratory, Richland, Washington 99352, USA;

6. 中国气象局广州热带海洋气象研究所, 广州 510640;

7. National Centre for Atmospheric Science, Department of Meteorology, University of Reading, Reading RG6 6BB, UK

* 通讯作者, E-mail: zhoutj@lasg.iap.ac.cn

收稿日期：2019-10-08; 收修改稿日期：2020-03-27; 接受日期：2020-04-15; 网络版发表日期：2020-05-13 中国科学院战略性先导科技专项项目(编号：XDA20060102)、国家重点研发计划项目(编号：2018YFC1507701)和国家自然科学基金项目(批 准号: 41775091)资助

摘要季风区生活着全球约 $2 / 3$ 的人口, 季风降水变化直接关系到当地的社会经济发展. 观测证据表明 20 世纪后 半叶以来全球陆地季风降水显著减少, 理解自然和人为强迫影响该变化趋势的物理过程, 对于未来水资源规划、 旱涝灾害风险管理、减缓与适应策略的制定具有重要意义。文章通过比较观测资料和第五次耦合模式比较计划 (CMIP5)5个全球气候模式不同外强迫试验模拟的1948 2005年全球陆地季风降水的变化，发现观测中全球陆地 季风降水的变干趋势与气候模式人为外强迫试验结果, 特别是人为气溶胶强迫试验的结果高度一致. 利用最优指 纹法的检测与归因分析表明，人为气溶胶强迫对该变干趋势的贡献为 $102 \%(5 \sim 95 \%$ 的不确定性范围为 $62 \sim 144 \%)$. 基于水汽收支分析比较热力和动力过程的贡献，发现人为气溶胶强迫主要通过减弱垂直水汽平流从而造成全球 陆地季风降水减少. 本文结果意味着如果未来季风区气溶胶排放不能得以控制, 则季风降水可能会继续减少; 而 中国自2006年以来气溶胶排放的显著下降趋势, 则有利于缓解季风区降水的减少趋势.

关键词全球季风, 降水, 检测和归因, 气溶胶强追, 动力热力过程

\section{1 引言}

全球季风由亚澳季风(含南亚/印度季风、东亚季
风、西北太平洋季风、澳洲季风)、非洲季风(北非季 风、东非季风)和美洲季风(南美季风、北美季风)组 成，全球季风区居住着世界上约 $2 / 3$ 的人口(Wang和

\footnotetext{
中文引用格式: 周天军, 张文霞, 张丽霞, 张学斌, 钱云, 彭冬冬, 马双梅, 董步文. 2020. 人为气溶胶导致全球陆地季风区降水减少的动力和热力过程. 中国科 学: 地球科学, 50: 1122-1137, doi: 10.1360/SSTe-2019-0237

英文引用格式: Zhou T, Zhang W, Zhang L, Zhang X, Qian Y, Peng D, Ma S, Dong B. 2020. The dynamic and thermodynamic processes dominating the reduction of global land monsoon precipitation driven by anthropogenic aerosols emission. Science China Earth Sciences, 63: 919-933, https://doi.org/10.1007/ s11430-019-9613-9
} 
Ding, 2008; Zhang等, 2018), 季风降水的变化对经济和 社会发展具有重要影响. 前人基于观测资料研究了 20 世纪全球陆地季风降水的长期趋势，发现1950年以来 陆地季风区降水经历了显著的减弱趋势(Wang和Ding, 2006; Zhou等, 2008a; Zhang和Zhou, 2011). 理解季风区 降水变化的原因对未来季风区的基础设施规划、水资 源管理和可持续发展政策的制定具有重要意义.

全球季风的变化受到多种因子的共同影响. 研究 表明，不同强迫因子例如温室气体(GHGs)(Kitoh等, 2013; Song等, 2014; Chen和Zhou, 2015)、人为气溶胶 (AAs)(Held等，2005；Lau等，2006；Meehl等，2008; Bollasina等, 2011; Qian等, 2011; Jiang等, 2013, 2015; Guo等, 2013; Wu等, 2013; Polson等, 2014; Song等, 2014; 吴国雄等, 2015; Li等, 2016; Zhang等, 2018)和气 候系统的自然内部变率(如太平洋多年代际振荡(IPO) 和大西洋多年代际振荡(AMO), 朱益民和杨修群, 2003；杨修群等，2004；Zhou等，2008b；Li等，2010; Wang等, 2012; Huang等, 2020), 都对季风变化具有显 著的影响，并且各种因子的影响呈现出明显的区域特 征, 包括影响的符号和程度(如Polson等, 2014; Pascale 等, 2017).

温室气体强迫对于季风环流具有两方面作用，一 方面通过增加海陆和南北半球间热力差异令东亚夏季 风增强，另一方面通过增加大气稳定度而使得Hadley 环流下沉支扩大、Walker环流减弱，从而令季风环流 减弱; 两种竞争机制最终使得东亚夏季风环流略微增 强(Song等, 2014; Lau和Kim, 2017). 温室气体强迫还 会引起海温不均匀的增暖, 进而影响季风环流. 20 世纪 后半叶, 热带西北太平洋海温增暖引起对流层低层环 流异常，并向南亚地区输送干冷空气，造成南亚季风 区降水减少(Annamalai等，2013). 人为气溶胶对季风 的影响则更为复杂. 尽管从统计的角度 20 世纪后半叶 北半球季风降水的减少趋势中可检测到人为气溶胶的 作用(Polson等, 2014), 但是驱动机制和具体的物理过 程则并不清楚. 亚洲季风区是多种类型的气溶胶最主 要的排放源地( $\mathrm{Li}$ 等, 2016); 在东亚季风区，气溶胶通 过减小海陆热力差异和增加大气稳定度, 从而减弱季 风环流(Song等，2014); 对于南亚季风区，气溶胶一方 面减少入射的太阳辐射造成地表冷却并减少局地蒸发 和大气中的水汽含量, 另一方面增强大气稳定度并减 弱海陆热力差异及南北半球能量收支差异，造成南亚
季风环流减弱、季风降水减少(Lau等, 2006; Bollasina 等, 2011; Salzmann等, 2014; Guo等, 2013). 此外, 不同 气溶胶类型对于不同地区的季风和降水影响(包括气 溶胶的局地作用和遥强迫作用)也不同(Jiang等，2013; Dong等, 2016; Wang等, 2017). 此外, 最近几十年土地 利用和土地覆盖的改变能够通过影响行星反照率和蒸 散发而造成季风降水减少(Krishnan等，2016; Paul等, 2016). 除了外强迫作用以外, 季风系统还受到气候内 部变率的影响. 在年代际-多年代际尺度上, 大西洋多 年代际振荡 (AMO) 和太平洋年代际振荡(PDO/IPO)可 通过影响Walker环流和Hadley环流，进而引起区域-半 球尺度上季风降水的变化(Zhou等, 2008b; Li等, 2010; Krishnamurthy和Krishnamurthy, 2014; Wang等, 2013; Jiang和Zhou, 2019). 综上, 全球季风系统的变化受到外 强迫和内部变率的共同作用, 过程极为复杂. 我们当前 关于观测中 20 世纪后半叶全球陆地季风降水减少的主 导因子和物理过程尚不清楚.

本文的目的是综合考虑各种外强迫因子以确定影 响全球陆地季风降水减弱趋势的主导因子, 定量估算 其贡献, 并从动力和热力过程来解释各种因子影响季 风区降水长期变化的物理机制. 为了理解自然变率(含 太阳辐射和火山气溶胶)和人为强迫(含混合均匀的温 室气体和人为气溶胶)的可能贡献, 本文采用 5 个气候 模式的集合模拟试验对观测的季风降水长期变化趋势 进行归因. 本文采用严格的“最优指纹”法来研究人类 活动的影响能否被检测到, 在此基础上, 再对全球陆 地季风降水的历史变化加以归因. 为理解导致全球陆 地季风变干的动力和热力过程, 本文还利用水汽收支 方法来揭示造成所检测到的降水历史变化的物理 机制.

\section{2 资料和方法}

\section{1 资料介绍}

本文通过比较 6 套逐月观测降水资料来衡量观测 降水变化的不确定性, 这6套资料具体包括: (1) 东安格 利亚大学气候研究中心的降水数据集CRU 4.01版本 (CRU)(Harris等, 2014); (2) 全球降水气候中心(GPCC) 的降水数据集Full V6版本(Schneider等, 2014); (3) 美 国特拉华大学(University of Delaware)降水数据集 V4.01版本(Delaware)(Willmott和Matsuura，2001); (4) 
美国国家海洋和大气管理局(NOAA)的陆地重建降水 量数据集(PREC/L)(Chen等, 2002); (5) 地表气候观测 变率分析的降水数据集(VASClimO, V1.1版本)(Beck 等，2005); (6) 全球历史气候数据网(GHCN)V2版本 (Peterson和Vose, 1997).

鉴于原始资料的分辨率互有不同，本文将所有资 料都插值到统一的 $2.5^{\circ} \times 2.5^{\circ}$ 的水平分辨率上. 由于VASClimO时段为1951 2000年，为了充分利用观测资料， 本文选取1948 2005年作为研究时段，取CRU、 GPCC、Delaware、PREC/L和 GHCN资料的集合平均 视为“观测”用于下文的分析. 需要指出的是, 分析发现 VASClimO资料揭示的1951 2000年全球陆地季风降 水也呈现出显著的减弱趋势(图1).

本文共分析了来自第五次耦合模式比较计划 (CMIP5) 5 个模式的 4 组试验. 这 5 个模式分别是 $\mathrm{Ca}-$ nESM2、CSIRO-Mk3-6-0、GFDL-CM3、GISS-E2-H 和GISS-E2-R. 如表1所示, 这四组试验不仅分别考虑 了温室气体、人为气溶胶强迫和自然强迫的作用，且 每个单独的强迫试验还包含多个成员(Taylor等, 2012). 这 5 个模式的 4 组试验共有 101 个成员数目的模 式输出，其中包含 32 个历史气候模拟试验、23个历史 温室气体模拟试验、23个历史人为气溶胶模拟试验,
以及 23 个历史自然强迫模拟试验. 历史气候模拟试验 (ALL-forcing)由自然强迫(太阳活动和火山气溶胶)和 人为强迫 (主要包括温室气体、人为气溶胶、臭氧和 土地利用)(见表1)共同驱动. 历史温室气体模拟试验 (GHG-forcing)、历史人为气溶胶模拟试验(AA-forcing)和历史自然强迫试验(NAT-forcing)分别单独考虑 温室气体、人为气溶胶和自然强迫因子的强迫作用, 其余驱动条件与ALL-forcing一致. 为便于分析, 所有 模式资料均采用双线性插值方法从其原始分辨率插值 到统一的 $2.5^{\circ} \times 2.5^{\circ}$ 分辨率的格点上, 模式中全球陆地 季风区的范围保持与观测严格一致.

\section{2 全球陆地季风区定义}

参照国际上的作法，全球陆地季风区定义为当地 气候平均的夏季与冬季降水之差大于 $2.0 \mathrm{~mm} \mathrm{day}^{-1}$, 并且当地夏季降水量超过全年总降水量 $55 \%$ 的区域 (Wang和Ding, 2008). 注意北半球夏季定义为5 9月, 冬 季为 11 月至来年3月; 南半球则相反.

\section{3 最优指纹检测与归因方法}

IPCC 科学评估报告及其指导性文件对气候变化 的检测与归因有明确定义(Hegerl等，2010；Bindoff等，
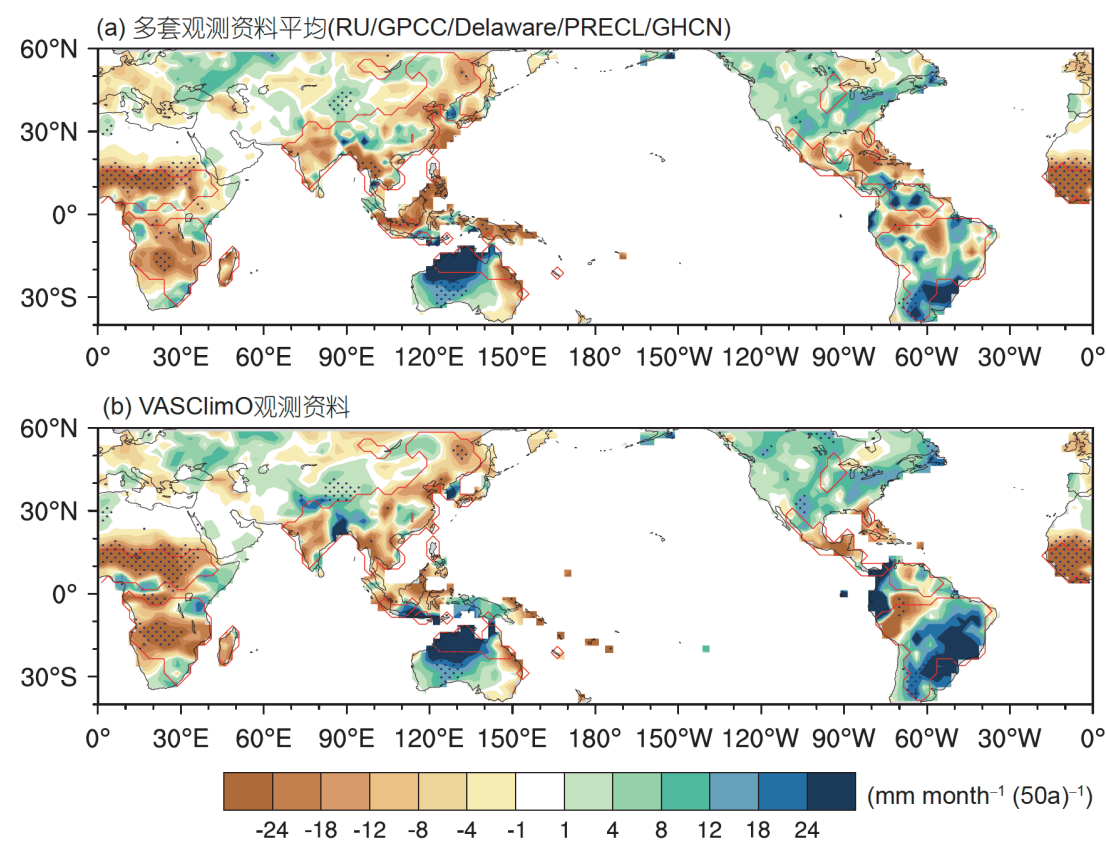

图 1 1950 2000年当地夏季降水线性趋势的水平分布

(a) CRU、GPCC、University of Delaware、PREC/L和GHCN五套观测资料集合平均结果; (b) VASClimO结果. 打点区域为通过 $5 \%$ 显著性水平 统计检验的区域, 红线区域为全球陆地季风区范围 
表 1 本文用到的CMIP5模式简介 ${ }^{\mathrm{a})}$

\begin{tabular}{|c|c|c|c|c|c|c|}
\hline \multicolumn{2}{|c|}{ 模式 } & CanESM2 & CSIRO-Mk3-6-0 & GFDL-CM3 & GISS-E2-H & GISS-E2-R \\
\hline \multirow{2}{*}{\multicolumn{2}{|c|}{ 研发机构 }} & CCCma & CSIRO-QCCCE & NOAA-GFDL & NASA-GISS & NASA-GISS \\
\hline & & Canada & Australia & USA & USA & USA \\
\hline \multicolumn{2}{|c|}{ 分辨率 } & $64 \times 128$ & $96 \times 192$ & $90 \times 144$ & $90 \times 144$ & $90 \times 144$ \\
\hline \multirow{4}{*}{ 模式集合成员数 } & ALL & 5 & 10 & 5 & 6 & 6 \\
\hline & GHG & 5 & 5 & 3 & 5 & 5 \\
\hline & AA & 5 & 5 & 3 & 5 & 5 \\
\hline & Nat & 5 & 5 & 3 & 5 & 5 \\
\hline \multirow{2}{*}{ 自然强迫因子 } & Solar & SOLARIS & SOLARIS & SOLARIS & SOLARIS & SOLARIS \\
\hline & Volcanic & S & S & S & S & S \\
\hline \multirow{2}{*}{ 人为强迫因子 } & GHG & IIASA & IIASA & IIASA & IIASA & IIASA \\
\hline & Aerosol & E1 & E2 & E1 & $\mathrm{C}$ & $\mathrm{C}$ \\
\hline
\end{tabular}

a) 所有模式均包含气溶胶的直接和间接效应. SOLARIS, http://sparcsolaris.gfz-potsdam.de/cmip5.php; S, Sato等(1993); C, 十年平均的逐 月气溶胶分布三维场, 利用Lamarque等(2010)驱动的CAM-Chem模式计算, 人为气溶胶包含有机碳 $(\mathrm{OC}) 、$ 黑碳 $(\mathrm{BC})$ 和二氧化硫 $\left(\mathrm{SO}_{2}\right) ; \mathrm{E} 1, \mathrm{La}-$ marque等(2010)的人为气溶胶; E2, 与E1相同, 但黑碳以 $25 \%$ 的速率均匀增加、有机碳以 $50 \%$ 的速率均匀增加(Rotstayn等, 2012)

2013). 若观测到的某种变化仅由内部变率导致的可能 性很小(如小于 $10 \%$ ), 则可认为这种变化被检测到了; 换言之，气候变化的检测是在一定的统计水平上证实 变化的发生, 而不提供变化发生的原因. 对于可检测 到的变化, 归因是指在给定的信度上，估算多种因子 对该变化的相对贡献(Hegerl等，2010；Bindoff等， 2013; 孙颖等, 2013).

在“最优指纹”检测与归因方法中，基于多元线性 回归模型，通过总体最小二乘法(TLS), 将观测的全球 陆地季风降水异常表示为模式模拟的外强迫响应信号 之和(Allen和Stott, 2003), 即

$y=\sum_{i=1}^{m} \beta_{i}\left(x_{i}-\varepsilon_{x_{i}}\right)+\varepsilon_{0}$,

式中, $y$ 是多套观测资料集合平均的全球陆地季风区夏 季降水异常， $x_{i}$ 表示模式集合平均模拟的对第 $i$ 个外强 迫因子的气候响应, 即全强迫、温室气体强迫、人为 气溶胶强迫和自然强迫等强迫下的“指纹”或信号. 每 个气候响应矩阵 $x_{i}$ 是模式中对第 $i$ 个外强迫的响应, $\varepsilon_{x_{i}}$ 为由于模式样本量有限导致的外强迫响应估算中的内 部变率噪音, $m$ 代表外强迫数, $\varepsilon_{0}$ 是与气候内部变率相 关的观测噪声, $\beta_{i}$ 为比例因子. 为提高长期变化的信噪 比, 将降水异常序列进行非重叠连续5年平均处理, 以 滤去年际振荡信号.

如果某个外强迫因子的比例因子显著大于零(即
比例因子的 $90 \%$ 置信区间下限大于零), 则认为模式模 拟的对该外强迫的响应在观测中可检测到. 进一步, 若 比例因子显著大于零、且其 $90 \%$ 置信区间包含 1 , 同时 其他强迫或因子的作用可被排除, 则认为模式模拟的 响应强度与观测变化是一致的, 观测中的变化可归因 于该强迫因子(Hegerl等，2010). 若比例因子 $\beta$ 大于(小 于) 1 , 则认为集合模拟低估(高估)观测的响应(Sun等, 2014).

基于最优指纹法对比例因子 $\beta$ 的估计, 可以进一步 估算不同外强迫因子对观测变化的贡献(如Allen和 Stott, 2003; Sun等, 2014; Xu等, 2015). 具体作法是将不 同外强迫下多模式集合平均模拟的线性趋势与该外强 迫因子对应的比例因子 $\beta$ 相乘，并基于 $\beta$ 的 $90 \%$ 置信区 间给出贡献的不确定性范围, 这一不确定性范围包括 观测和模式模拟中气候系统内部变率的影响.

为了估计内部变率(即“噪音”), 本文采用工业革命 前控制试验和历史模拟试验的成员间离差两组估计来 增加样本量. 一方面, 我们采用来自 22 个CMIP5气候模 式共计12489年的工业革命前控制试验, 将其分成非重 叠的58年片段(与观测等长), 共计有 204 个片段 (见表 2). 另一方面, 我们还计算了历史模拟试验集合成员间 的离差(即每个模式的各自历史模拟试验成员与该模 式相应试验的集合平均的差值), 共包含 101 个历史模 拟试验成员(见表1)。本文选取各模式历史模拟试验 


\section{表 2 本文中用于估计内部变率的CMIP5模式列表 ${ }^{a)}$}

\begin{tabular}{cccc}
\hline 序列 & 模式 & $\begin{array}{c}\text { 时间长度 } \\
\text { (年) }\end{array}$ & $\begin{array}{c}\text { 非重叠58年 } \\
\text { 片的个数 }\end{array}$ \\
\hline 1 & bcc-csm1-1 & 500 & 8 \\
2 & BNU-ESM & 559 & 9 \\
3 & CCSM4 & 501 & 8 \\
4 & CNRM-CM5 & 600 & 10 \\
5 & CSIRO-Mk3-6-0 & 500 & 8 \\
6 & CanESM2 & 996 & 17 \\
7 & FGOALS-g2 & 900 & 15 \\
8 & GFDL-CM3 & 500 & 8 \\
9 & GISS-E2-H & 480 & 8 \\
10 & GISS-E2-R & 850 & 14 \\
11 & HadGEM2-ES & 336 & 5 \\
12 & IPSL-CM5A-LR & 1000 & 17 \\
13 & MIROC-ESM & 531 & 9 \\
14 & MIROC-ESM-CHEM & 255 & 4 \\
15 & MRI-CGCM3 & 500 & 8 \\
16 & NorESM1-M & 501 & 8 \\
17 & ACCESS1-0 & 250 & 4 \\
18 & CESM1-CAM5 & 319 & 5 \\
19 & FGOALS-s2 & 501 & 8 \\
20 & HadGEM2-CC & 240 & 4 \\
21 & MIROC5 & 670 & 11 \\
22 & MPI-ESM-LR & 1000 & 17 \\
\hline
\end{tabular}
的整体飘移

a) 通过减去在整个模拟时段的长期线性趋势扣除控制试验中

1890 2005年的模拟输出结果, 共有 2 个 58 年的片段, 因 此集合成员间离差共得到202个“噪音”片段. 我们参照 前人的作法, 把总计 406 个噪音片段分为独立的数目相 等的两组(每组包含101个成员间离差“噪音”片段和 102 个控制试验“噪音”片段), 一组用于最优估计，一组 用于残差一致性检验(即模式模拟的内部变率是否一 致于观测中的变率)(Allen和Tett, 1999; Zhang等, 2007; $\mathrm{Xu}$ 等, 2015).

参照前人的作法，我们通过选取模式模拟的内部 变率的经验正交函数(EOFs) 主导模态进行降维(如 Zhang等, 2007; Sun等, 2014; Xu等, 2015), 然后对全球 陆地季风区夏季降水的长期变化进行最优指纹法分 析. 我们根据残差一致性检验结果来选取EOF主导模
态的数量(Allen和Tett, 1999; Allen和Stott, 2003), 并通 过选取不同的 $\mathrm{EOF}$ 主导模态数验证了检测结果的稳 健性.

\section{4 水汽收支方法}

降水可以表示为蒸发、垂直积分水汽输送的辐合 辐散及残差项之和(Chou等, 2013a):

$P=E-<\nabla \cdot \mathbf{V} q>+\delta$,

式中, $P 、 E$ 和 $\mathrm{V}$ 分别代表降水、蒸发和风场, $q$ 为比湿, $-<\nabla \cdot \mathbf{V} q>$ 则为垂直积分水汽输送的辐合辐散. $-<\nabla \cdot \mathbf{V} q>$ 可进一步分解为两项, 即垂直水汽平流 $\left(-<\omega \partial_{\mathrm{p}} q>\right)$ 和水平水汽平流 $\left(-<\mathbf{V}_{\mathrm{h}} \cdot \nabla_{\mathrm{h}} q>\right)$. 所以, 降水变化可以表示为蒸发变化、水平水汽平流变化、 垂直水汽平流变化和残差项, 如公示(3)所示:

$P^{\prime}=E^{\prime}-<\omega \partial_{\mathrm{p}} q>^{\prime}-<\mathbf{V}_{\mathrm{h}} \cdot \nabla_{\mathrm{h}} q>^{\prime}+\delta^{\prime}$,

式中, 角分符号表示较之气候平均的偏差, 下标 $\mathrm{p}$ 和 $\mathrm{h}$ 分 别代表气压和水平方向, $\mathbf{V}_{\mathrm{h}}$ 是水平矢量风, $\nabla_{\mathrm{h}}$ 是水平 微分算子.

垂直水汽平流的变化 $-<\omega \partial_{\mathrm{p}} q>$ '可进一步分解为 三项之和: 一是由水汽含量变化, 也就是热力作用引起 的异常水汽辐合项 $-<\bar{\omega} \partial_{\mathrm{p}} q>^{\prime}$; 二是由大气环流变化 也就是动力作用引起的异常水汽辐合项 $-<\omega^{\prime} \partial_{\mathrm{p}} \bar{q}>$; 第三是非线性项 $-<\omega^{\prime} \partial_{\mathrm{p}} q^{\prime}>$. 注意上横线表示气候平 均. 其中 $-<\bar{\omega} \partial_{\mathrm{p}} q^{\prime}>$ 与水汽含量变化有关, 主要受温度 变化的调制; $-<\omega^{\prime} \partial_{\mathrm{p}} \bar{q}>$ 与垂直速度变化有关, 主要 受大气环流变化的影响. $-<\omega^{\prime} \partial_{\mathrm{p}} q^{\prime}>$ 同时受到垂直环 流和水汽含量变化的影响, 但往往很小故可忽略不计. 所以, 公式(3)可近似表达为

$P^{\prime} \approx E^{\prime}-<\bar{\omega} \partial_{\mathrm{p}} q^{\prime}>-<\omega^{\prime} \partial_{\mathrm{p}} \bar{q}>-<\mathbf{V}_{\mathrm{h}} \cdot \nabla_{\mathrm{h}} q>^{\prime}$.

需要指出的是, 降水和蒸发的变化相互耦合, 水汽 收支分析无法揭示两者之间的因果关系. 本文使用月 平均水汽和环流场来诊断水汽收支, 因此其残差项可 能来源于月以下尺度的瞬变浴动, 地形引起的地表过 程的贡献, 以及气候模式本身的水分不平衡(Liepert和 Lo, 2013). 由于残差项的量级相对较小, 本文不做 讨论. 


\section{3 结果分析}

\section{1 模拟和观测比较}

我们首先比较 5 套观测降水资料所揭示的全球陆 地季风夏季降水在1948 2005年间的变化趋势(图2a). 5套资料的集合平均降水在1948 2005年呈现出显著 的减弱趋势(图2a), 趋势为 $-10.55(-5.39 \sim-14.34) \mathrm{mm}$ month $^{-1}(58 \mathrm{a})^{-1}$ ，约为1961 1990年间气候平均的 $-5.92 \%(-3.02 \sim-8.22 \%)$, 通过 $1 \%$ 水平的显著性检验 (图2b). 注意尽管减弱趋势的强度有所不同，但5套观 测资料均一致地呈现出显著的减弱趋势．这一减弱趋 势与前人基于不同资料得到的结果一致(Wang和Ding, 2006; Zhou等, 2008a, 2008b; Zhang和Zhou, 2011), 表明 这一变干趋势是可信的, 不依赖于观测资料的选取.

为理解自然强迫和人为强迫对观测到的全球陆地 季风区显著变干趋势的潜在贡献, 我们采用 CMIP5 的 5 个耦合气候系统模式的集合模拟结果，把模拟的全球
陆地季风降水的变化与观测结果进行比较. 模式性能 评估表明，这 5 个模式能合理再现全球陆地季风区当 地夏季降水的气候态分布，在 $2.5^{\circ} \times 2.5^{\circ}$ 的水平分辨率 上，历史气候模拟试验的多模式集合平均 $(\mathrm{MME})$ 季风 降水气候态空间分布与多种观测资料集合平均之间的 空间相关系数为 0.84 (只包含陆地季风区), 这为我们下 面利用模拟结果来研究降水的长期变化及其物理机理 提供了可靠的基础(图3a和3b).

我们首先分析全球陆地季风区当地夏季的降水距 平变化, 这里的基准气候态取1961 1990年平均值. 历 史强迫试验的集合平均(ALL-forcing)较好地刻画出全 球陆地季风区夏季的变干趋势(图2a), 多模式集合平 均值的变干趋势为 $-6.49 \mathrm{~mm} \mathrm{month}^{-1}(58 \mathrm{a})^{-1}$, 约为 1961 1990年气候平均值的 $-3.89 \%$ ，这处于多套观测 资料长期趋势的不确定性范围之内(图2b). 历史模式 试验在全球陆地季风区夏季降水减弱趋势方面与观测 的一致性，表明外强迫对全球陆地季风区夏季降水的

(a) 降水时间序列

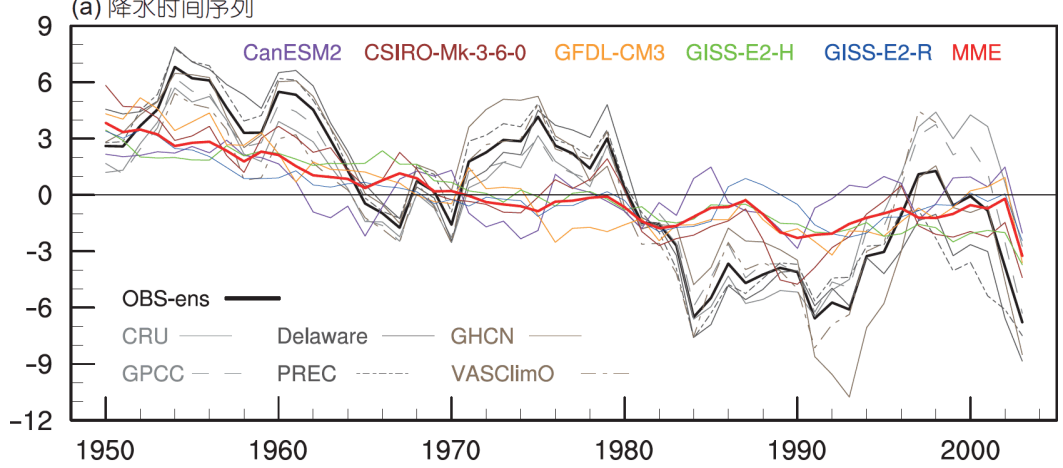

(b) 降水线性趋势

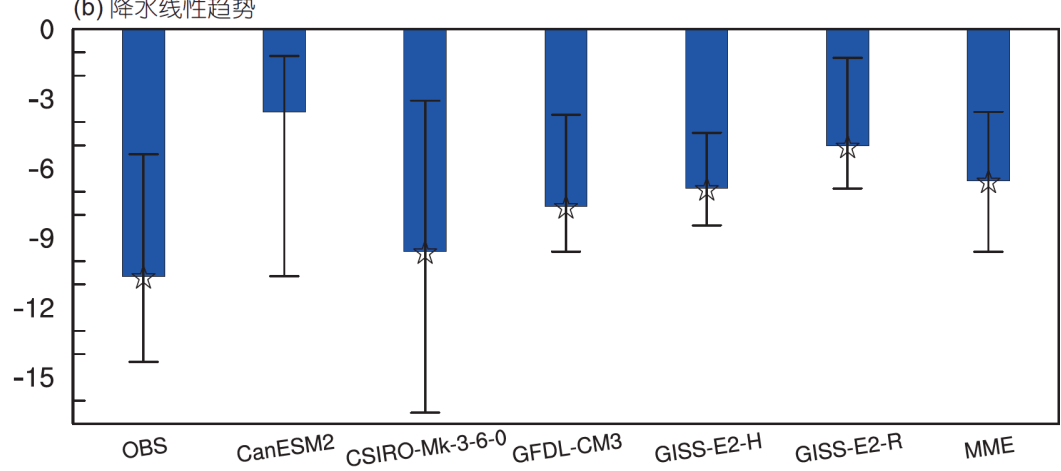

图 2 1948 2005年全球陆地季风区夏季降水变化

(a) 多套观测和5个CMIP5模式历史气候模拟试验(ALL-forcing)模拟的全球陆地季风区夏季降水异常(单位: $\mathrm{mm} \mathrm{month}^{-1}$ )时间序列，降水异常 是相对于1948 2005年均值的异常的5年滑动平均. 细黑线表示除VASClimO(只涵盖1950 2000年)以外的5套再分析资料集合平均结果，红色 粗线为历史气候模拟试验多模式集合平均(MME)结果. (b) 全球陆地季风区夏季降水的线性趋势(单位: $\mathrm{mm} \mathrm{month}^{-1}(58 \mathrm{a})^{-1}$ ), 垂直柱是集合 平均趋势, 误差线是不同成员之间的离差范围, 五角星表示集合平均趋势通过 $5 \%$ 显著性水平的统计检验 
变化有贡献.

我们进一步比较不同分离强迫试验集合平均模拟 的全球陆地季风区夏季降水趋势, 发现全强迫试验中 的变干趋势主要来自人为气溶胶的强迫作用(图 $4 \mathrm{a}$ 和 $4 \mathrm{~b})$, 并且 5 个气候模式一致地模拟出人为气溶胶强迫 的主导作用(图4b). 比较而言, 温室气体和自然强迫试 验中MME模拟的全球陆地季风夏季降水变化趋势较 弱, 并未通过 $5 \%$ 水平的显著性检验(图 $4 \mathrm{a}$ 和 $4 \mathrm{~b}$ ).

\section{2 人为强迫影响的检测和归因}

我们采用“最优指纹”法来定量比较观测和模拟的 全球陆地季风区夏季降水的变化. 我们基于 5 个模式的 集合平均采用“单信号”方法来进行检测归因．对于全 球陆地季风区夏季降水变化而言, 在全强迫(ALL-forcing)和人为气溶胶强迫(AA-forcing)试验中, 最优指纹 法计算的比例因子在各模式集合平均中均显著大于
零，表明全强迫和人为气溶胶强迫对全球陆地季风区 夏季降水减少的影响是“可检测到”的. 全强迫与人为 气溶胶强迫下，比例因子一致于 1 , 说明全球陆地季风 区夏季降水的减少可归因于人为气溶胶排放的影响 (图4c). 关于结果的稳健性, 基于单个模式的检测归因 结果一致表明全强迫与人为气溶胶强迫对全球陆地季 风区夏季降水减少的作用可以被检测到(图4c), 若将 考虑的EOF模态个数从 5 个逐渐增加到 10 个也均支持 上述结论(图5). 注意温室气体和自然强迫的影响不能 被显著地检测到(未通过残差一致性检验或比例因子 的范围包含零), 并且其结果具有较大的模式不确定性 (图4c 和图5). 检测到的人类活动对季节降水变化的影 响不同于其对区域极端降水变化的影响. 例如，温室 气体强迫对观测到的中国东部极端强降水增加趋势可 以被检测到, 人为气溶胶强迫可以部分抵消温室气体 强迫的影响, 但是其对极端事件的影响无法通过最优

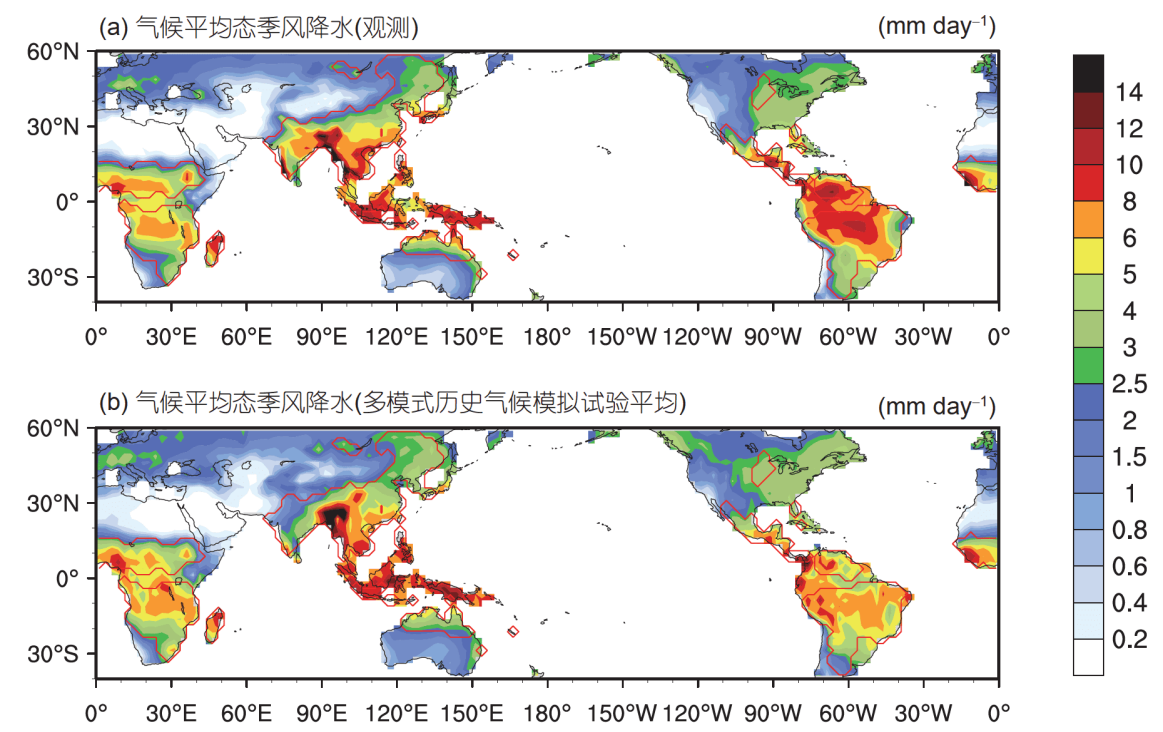

(c) 水汽收支(多模式历史气候模拟试验平均)

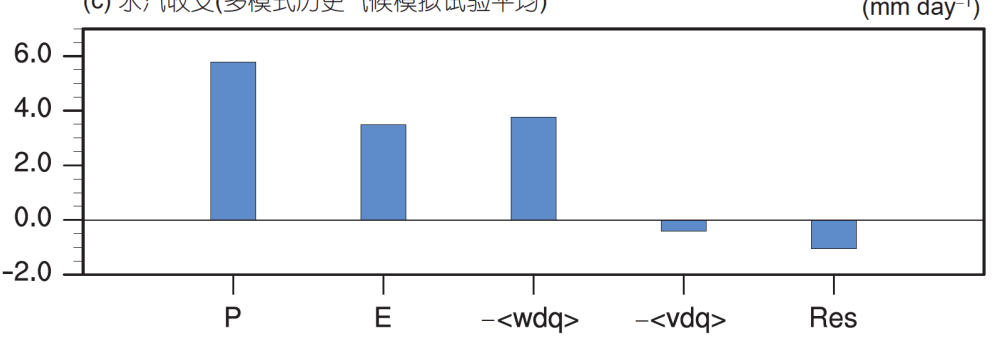

图 3 全球陆地季风气候态夏季降水分布

(a) 观测; (b) 历史气候模拟试验MME结果, 红线区域为全球陆地季风区范围; (c) 历史气候模拟试验MME模拟的全球陆地季风区平均的夏季 水汽收支. $\mathrm{P}$ 和 $\mathrm{E}$ 分别为降水和蒸发, $-<\mathrm{wdq}>$ 为垂直水汽平流项, $-<\mathrm{vdq}>$ 为水平水汽平流项, Res 为残差项 


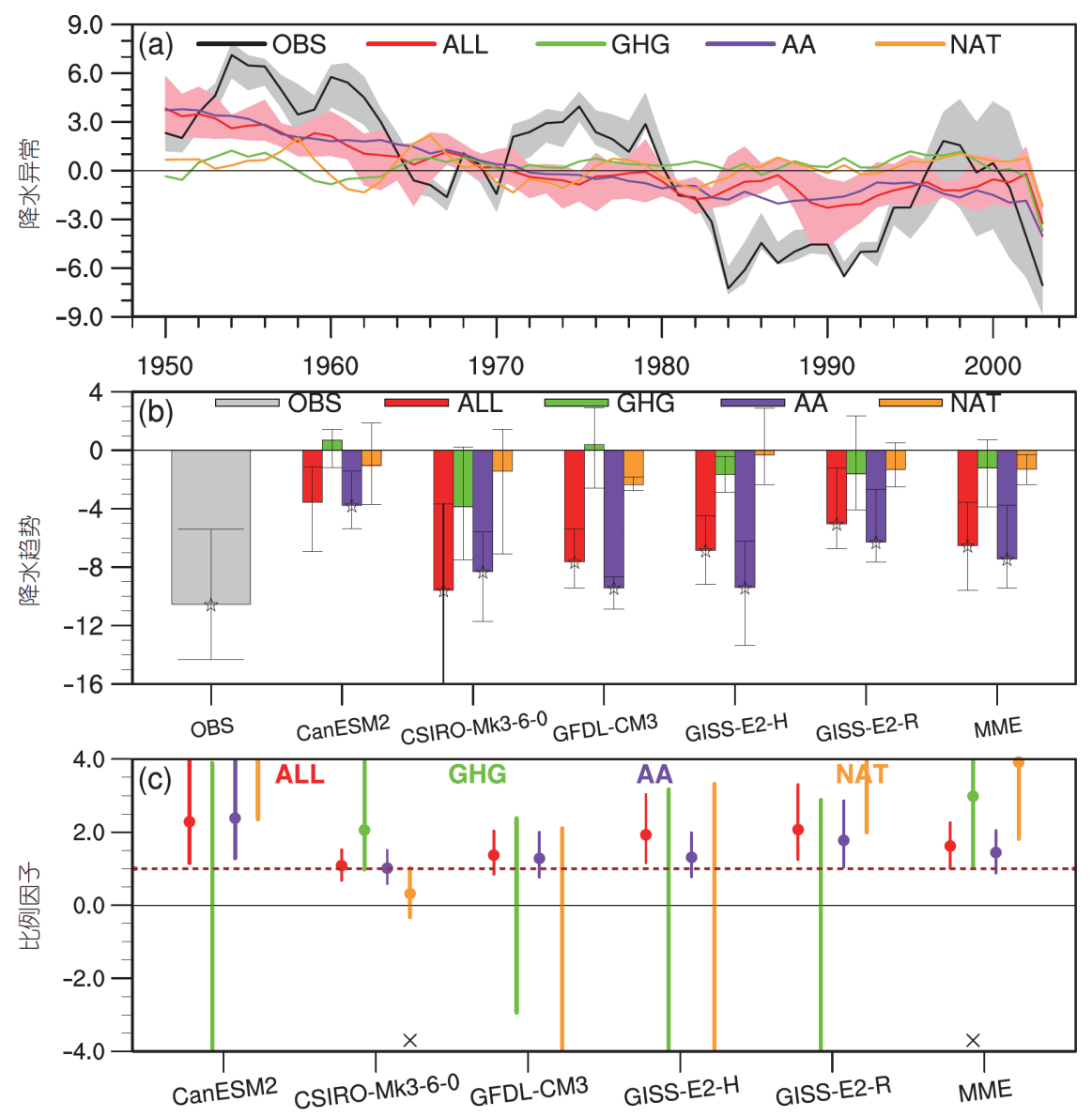

图 4 不同强迫影响下全球陆地季风区夏季降水变化的检测与归因

(a) 多观测资料集合平均和4组分离强迫历史气候模拟试验多模式集合平均中, 较之1948 2005年均值的全球陆地季风区夏季降水5年滑动平 均(单位: $\mathrm{mm} m \mathrm{monh}^{-1}$ ). 灰色和粉色阴影分别代表不同观测和历史气候模拟试验的离差范围. (b) 全球陆地季风区夏季降水的线性趋势(单位: $\left.\mathrm{mm} \mathrm{month}^{-1}(58 \mathrm{a})^{-1}\right)$. 垂直柱表示集合平均的趋势, 通过 $5 \%$ 显著性水平统计检验的用五角星加以标注, 误差线代表不同成员之间的离差. (c) 最 优指纹检测结果(选取 10 个EOF主导模态). 实心圆和误差线分别为对应比例因子的最优估计值和 5 95\%不确定性范围. (a) (c)中红色、绿色、 紫色和橙色分别代表全强迫、温室气体强迫、人为气溶胶强迫和自然强迫

指纹法而检测到(Ma等, 2017).

为估计不同外强迫因子对季风区降水变干趋势的 贡献, 我们将每个分离强迫试验MME的线性趋势与单 因子检测得到的比例因子相乘，如图6所示. 结果表明, 人为强迫对观测的全球陆地季风夏季降水在 1948 2005年间变干趋势的贡献为 100\%(5 95\%的不 确定性范围为 $63 \sim 140 \%$ ), 其贡献值为 $-10.55 \mathrm{~mm}$ $\operatorname{month}^{-1}(58 \mathrm{a})^{-1}$, 其中人为气溶胶排放对该变干趋势的 贡献为 $102 \%(62 \sim 144 \%)$.

\section{3 不同人为因子影响降水的物理过程}

我们进一步检查全球陆地季风区夏季降水线性趋
势的空间分布情况. 在观测中, 变干趋势显著的区域位 于北非和南非季风区、南亚和东亚季风区、澳洲季风 区局部，以及北美和南美季风区大部分地区(图7a). 整 体而言, 全强迫MME模拟的全球陆地季风区夏季降水 的变干趋势分布与观测具有一致的空间分布特征(图 $7 b$ ); 与观测不一致的地方主要表现在MME高估了南 美季风区东部的变干趋势, 同时低估了北非季风区东 部的变干趋势. 比较各分离强迫试验, 结果进一步证 明人为气溶胶强迫对南亚和东亚季风区、南美和北美 季风区及非洲季风区部分地区变干趋势的主导作用 (图7c). 分析表明, 温室气体强迫有利于南亚和东亚季 风区、非洲部分季风区夏季降水增加(图7d), 因此, 温 

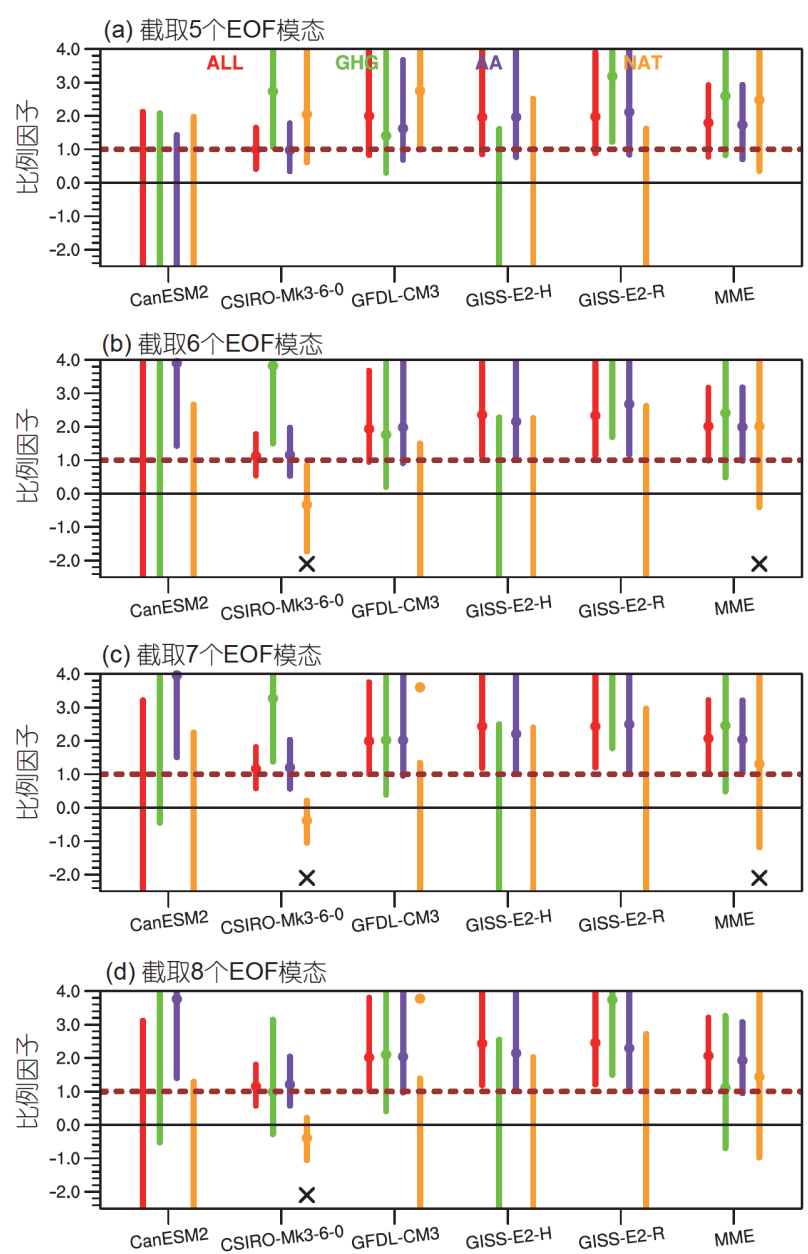

(e) 截取 9 个EOF模态

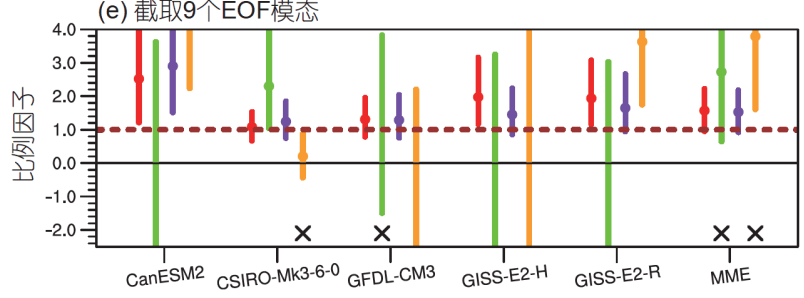

图 5 EOF模态取为5 9个时最优指纹归因结果

实心圆圈和误差线分别为比例因子的最优估计值和 5 95\%不确定 性范围. 叉符号表示未通过显著性水平为 $10 \%$ 的残差一致性检验. 当 EOF模态变化范围为5 10时, 温室气体强迫和人为气溶胶强迫的作 用可以被检测到

室气体强迫的作用是部分抵消气溶胶强迫造成的变干 趋势(图7c). 值得注意的是，温室气体强迫同样有利于 美洲季风区夏季变干(图7d), 这与前人基于 $\mathrm{CO}_{2}$ 增加试 验得到的温室气体通过增加大气稳定度令该地区变干 的结论一致(Pascale等, 2017). 注意自然强迫MME不存 在显著的线性趋势(图7e).

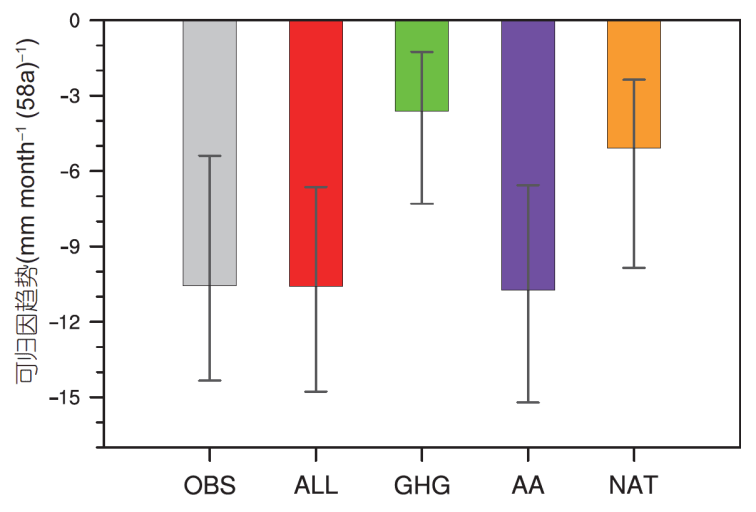

图 6 采用单信号最优估计得到的人为强迫、温室气体强 迫、人为气溶胶强迫和自然强迫对全球陆地季风区夏季变 干趋势的贡献

不同颜色的误差线为 5 95\%不确定性范围，其中观测(灰色柱)为 5 套 观测资料的集合平均, 误差线为 5 套观测资料的不确定性范围

为了理解人为强迫影响全球陆地季风区降水变化 的物理过程, 我们分析了全球陆地季风区1948 2005年 当地夏季水汽收支各项的长期趋势. 降水与蒸发和垂 直积分的水汽通量散度相互平衡，水汽通量的辐合辐 散可进一步分解为水平水汽平流项和垂直水汽平流 项，后者进一步分为热力项(TH)和动力项(DY)及非线 性项, TH和DY分别由水汽含量和大气环流变化决定, 其变化被称作热力项和动力项的作用结果. 就气候平 均而言, 全球陆地季风区降水主要由蒸发和垂直水汽 平流项来平衡，其中水平水汽平流项和残差项的贡献 很小, 可忽略不计(图3c).

水汽收支分析表明, 就1948 2005年全强迫和人为 气溶胶强迫试验模拟结果来看, 全球陆地季风区夏季 降水的变干趋势主要由垂直水平平流项主导, 热力项 $\mathrm{TH}$ 和动力项DY均有显著贡献(图8a). 在温室气体强迫 试验中，温室气体增加导致气温升高，大气比湿增加， 垂直水汽平流的热力项呈现增加趋势; 与此同时热带 大气静力稳定度增加, 大尺度大气环流减弱(Held和 Soden, 2006; Schneider等, 2010; Chou等，2013a， 2013b), 使得动力项作用减弱. 因此, 温室气体强迫对 水汽平流变化的整体影响较弱. 气溶胶强迫会使得垂 直水汽平流的动力项 $\mathrm{DY}$ 和热力项 $\mathrm{TH}$ 作用均减弱，总 的变化由热力项作用占主导(图8a).

人为气溶胶和温室气体如何影响热力项变化? 分 析表明，气溶胶强迫可以导致地表冷却，大气比湿减 少，进而减弱热力项作用，该特征在全球陆地季风区 


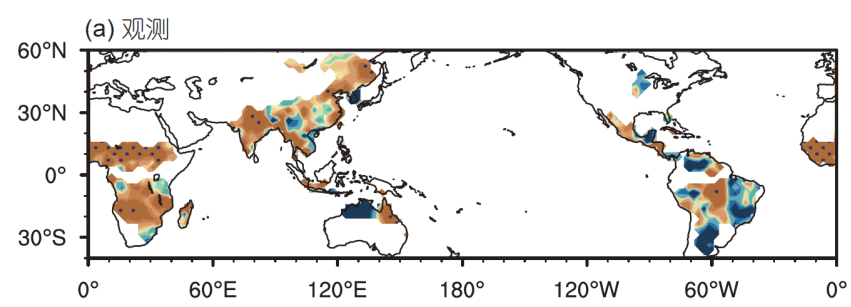

(b) 多模式全强迫试验平均

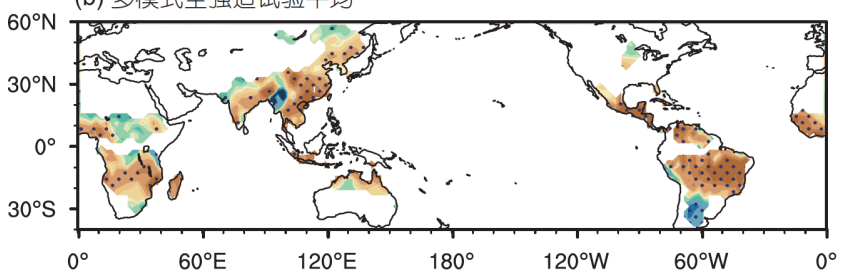

(d) 多模式温室气体强迫试验平均

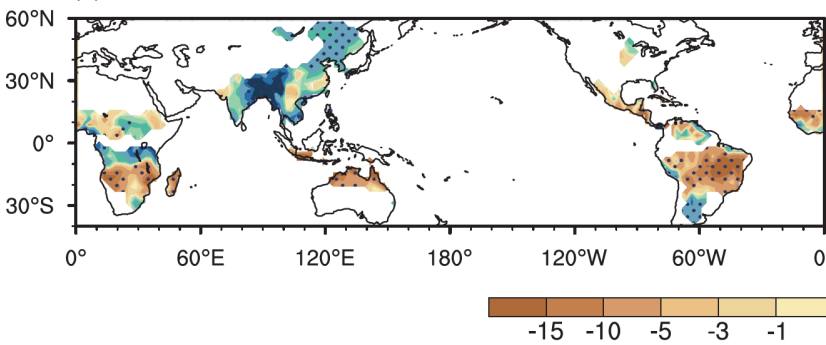

(c) 多模式人为气溶胶强迫试验平均

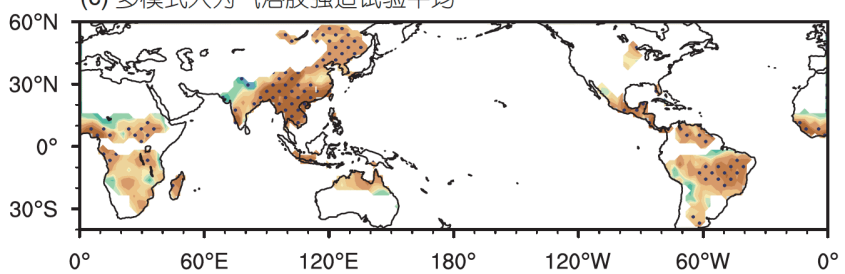

(e) 多模式自然强迫试验平均

图 7 观测和不同强迫因子模拟的 1948 2005年全球陆地季风区当地夏季降水的线性趋势的水平分布

(a) 多套观测降水资料集合平均; (b) ALL-forcing集合平均; (c) AA-forcing集合平均; (d) GHG-forcing集合平均; (e) NAT-forcing集合平均. 打点 区域表示线性趋势通过了 $5 \%$ 显著性水平统计检验, 只给出全球陆地季风区范围

的所有子区域均显著(图8c 和图8e ). 相反，温室气体会 增加地表温度, 增加大气比湿, 增强热力项作用, 该现 象在全球陆地季风区各区域同样显著(图8g和图8i).

关于人为气溶胶和温室气体的不同作用，对整层 积分的可降水量变化进行比较, 发现全强迫试验中温 室气体强迫可部分抵消人为气溶胶强迫所减少的大气 可降水量(图9). 因此，温室气体强迫和气溶胶强迫均 能通过热力作用影响季风区的水汽变化，只是二者的 作用相反.

人为气溶胶和温室气体如何影响动力项变化? 分 析表明，温室气体强迫与人为气溶胶强迫对水汽平流 的动力项的作用一致, 均能够令其减少(图8a). 一般认 为, 温室气体增加导致的全球变暖，使大气静力稳定 度增加，会减弱热带大尺度大气环流(Held和Soden, 2006; Schneider等, 2010; Chou等, 2013b; Lau和Kim, 2017; Pascale等, 2017), 进而减弱季风区的大气环流 强度及动力项强度. 气溶胶强迫中水汽平流的动力项 减弱, 主要原因在于气溶胶强迫造成季风环流减弱,
因为人为气溶胶强迫使得陆地变冷强度大于相邻海 洋, 北半球变冷强度大于南半球, 进而海陆热力对比 和南北半球热力对比强度减弱, 最终令季风环流减弱 (Lau和Kim，2017). 我们进一步比较了温室气体和气 溶胶强迫对表面温度(图10)和地表辐射通量(图11)的 影响, 温度的变化支持上述观点(图10), 气溶胶-辐射 和气溶胶-云相互作用导致的向下短波辐射减少起主 导作用(图11).

最后，本文关注的是陆地季风区的整体情况，我 们需要同时认识到各个子季风区之间的差异, 温室气 体强迫导致的动力项减弱在所有陆地子季风区都较 为显著, 但人为气溶胶强迫造成的动力项变化却呈现 区域不一致性特征，其中亚洲季风区和美洲季风区的 减弱趋势较弱但通过了 $5 \%$ 水平的显著性检验，非洲 季风区部分地区的动力项却呈现增加趋势. 关于子季 风区环流的动力项对人为气溶胶强迫的响应需要进 一步研究，这有赖于分辨率更高的全球或者区域气候 模式. 
(a) 水汽收支各项线性趋势
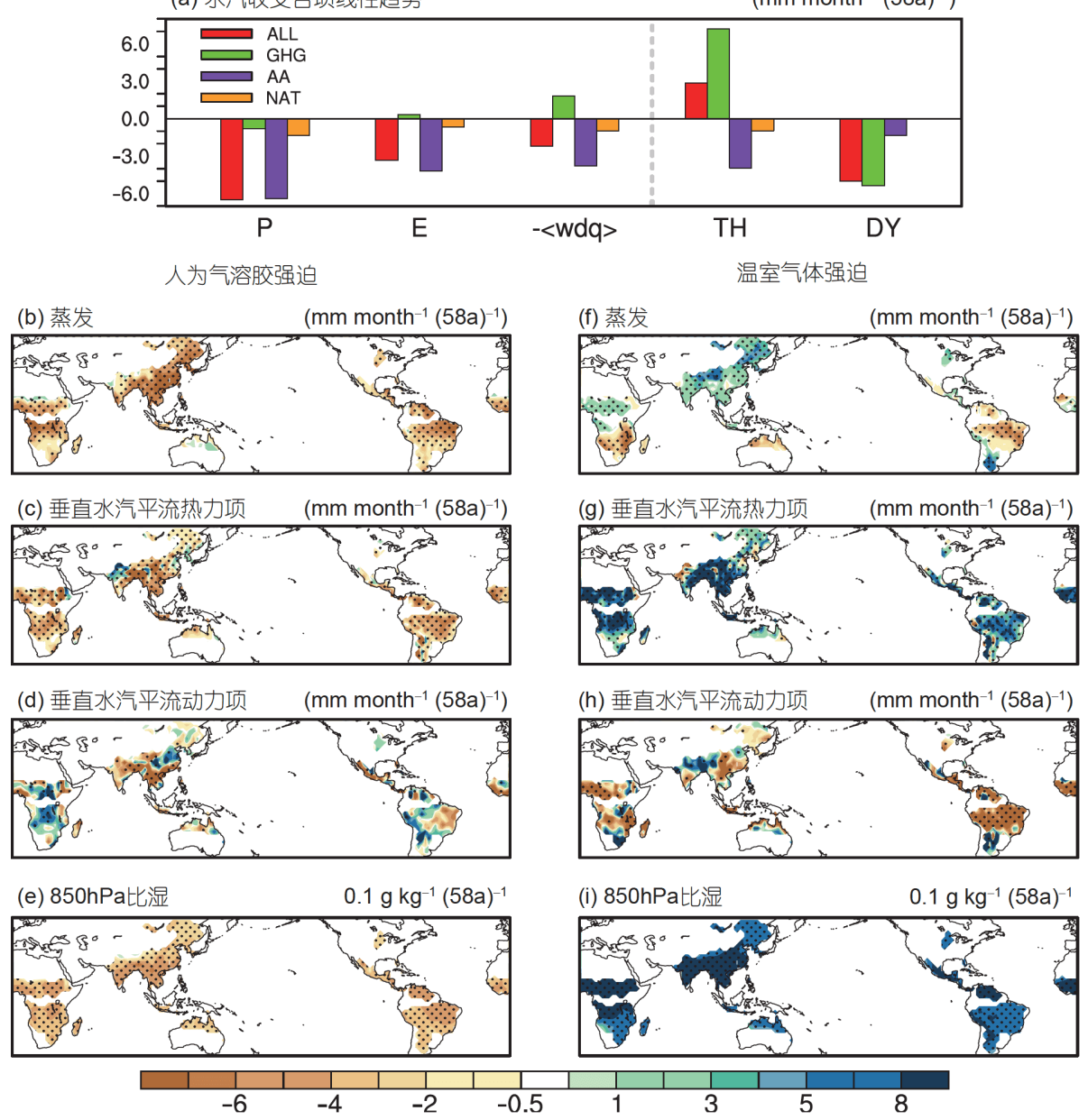

图 8 全球陆地季风区夏季降水变干趋势的水汽收支分析

(a) 全球陆地季风区区域平均的水汽收支各项的线性趋势, 其中垂直水汽平流项 $(-<\mathrm{wdq}>$ )分为热力(TH)和动力(DY)两项. 红色、绿色、紫色 和橙色柱分别代表ALL-forcing、GHG-forcing、AA-forcing和NAT-forcing集合平均结果. (b) (i)为AA-forcing和GHG-forcing集合平均的 1948 2005年线性趋势的水平分布, 左列为AA-frocing结果, 右列有GHG-forcing结果. 打点区域通过 $5 \%$ 显著性水平统计检验

\section{4 结论}

针对1948 2005年间全球陆地季风区夏季降水的 显著减少趋势，本文采用CMIP5模式结果基于最优指 纹法的分析表明，人为强迫的作用可以被检测到. 基 于最优指纹检测结果的归因分析表明，观测的降水减 少趋势 $\left(-10.55 \mathrm{~mm} \mathrm{month}{ }^{-1}(58 \mathrm{a})^{-1}\right)$ 主要归因于人为气 溶胶强迫的作用，其贡献率为 $102 \%$ (不确定性范围为 62 144\%). 围绕着外强迫影响季风区降水变化的物理 过程, 水汽收支诊断表明, 人为气溶胶强迫主要通过减 弱垂直水汽平流作用令全球陆地季风区降水显著减 少.气溶胶的冷却作用对降水变化具有双重贡献: 既能
通过减少大气湿度来减弱热力项强度, 又能通过减弱 季风环流来削弱动力项的强度，二者共同作用使得垂 直水汽平流减弱，导致季风区降水减少。温室气体强 迫对季风区降水同样具有双重贡献，一是令大气湿度 增加, 热力项作用增强, 二是增加大气稳定度令动力 项作用减弱，二者互相抵消，最终令温室气体的整体 作用是使得全球陆地季风区夏季降水仅呈现出微弱的 变湿趋势.

综上，本文研究表明人为气溶胶强迫对全球陆地 季风夏季变干趋势具有显著作用，结果对未来季风区 的气候变化减缓及适应政策的制定具有重要指示意 义. 全球季风区的大部分地区, 特别是印度, 正经历着 
(a) 全强迫试验
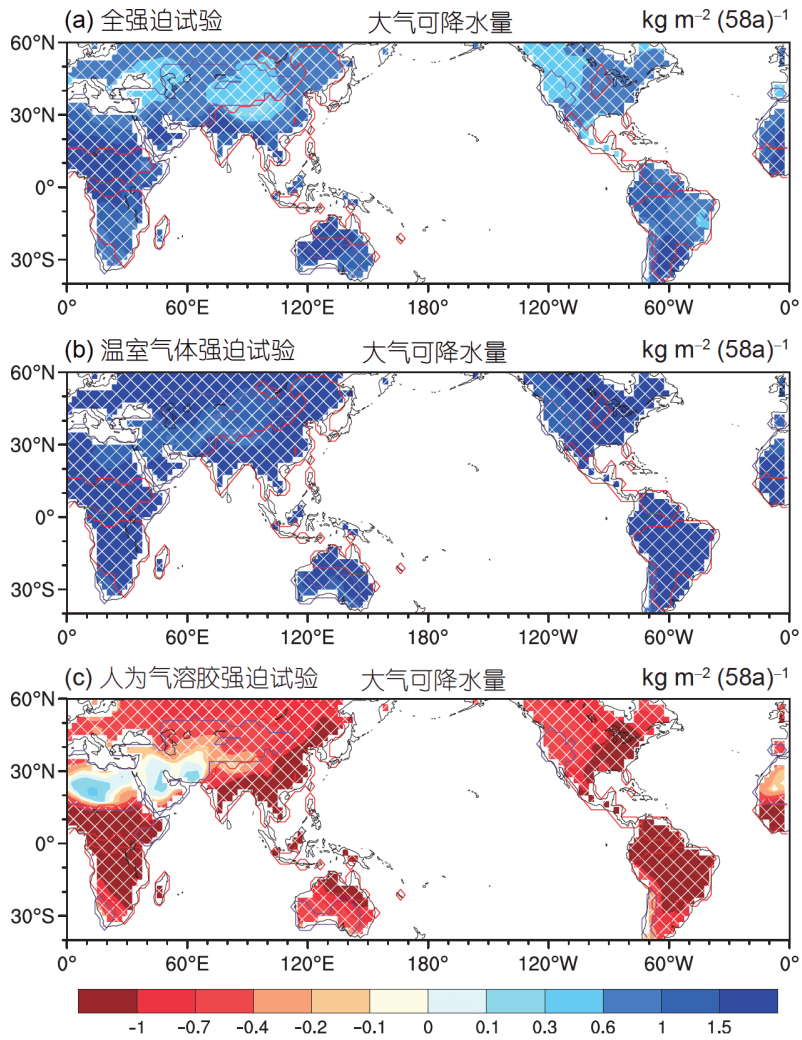

图 $91948 \sim 2005$ 年当地夏季大气可降水量线性趋势的水平 分布

(a) ALL-forcing多模式集合; (b) GHG-forcing多模式集合; (c) AAforcing多模式集合. 斜线区域通过了 $10 \%$ 显著性水平统计检验, 红色 实线为全球陆地季风区范围

社会经济的快速发展和气溶胶排放的快速增长时期 (Li等, 2016), 未来如果不采取有效措施来减少气溶胶 排放, 季风区降水可能会持续减少, 从而对水资源产生 重要影响. 中国改革开放以来经历了几十年的经济快 速发展期，统计数据显示自1980 2005年，中国的人为 硫酸盐等气溶胶的排放呈持续上升趋势，但可喜的是 自2006年开始，伴随着能源结构的调整，人为气溶胶 排放开始呈现出减少的趋势(Li等, 2017), 这种变化不 仅对于改善空气质量、提高人居环境具有积极意义, 同时对于季风区水资源的改善也有重要价值. 受限于 模式资料, 本文关注时段为1948 2005年, 1979年之后, 全球季风区降水已经开始有所恢复(Wang等, 2013; Lin 等, 2014), 虽然有研究指出温室气体强迫对1979年之 后的增加趋势有所贡献(Wang等, 2013; Zhang和Zhou, 2014), 但目前仍缺乏严格的检测归因研究定量分析不 同外强迫因子对全球季风降水增加趋势的相对贡献. (a) 全强迫试验
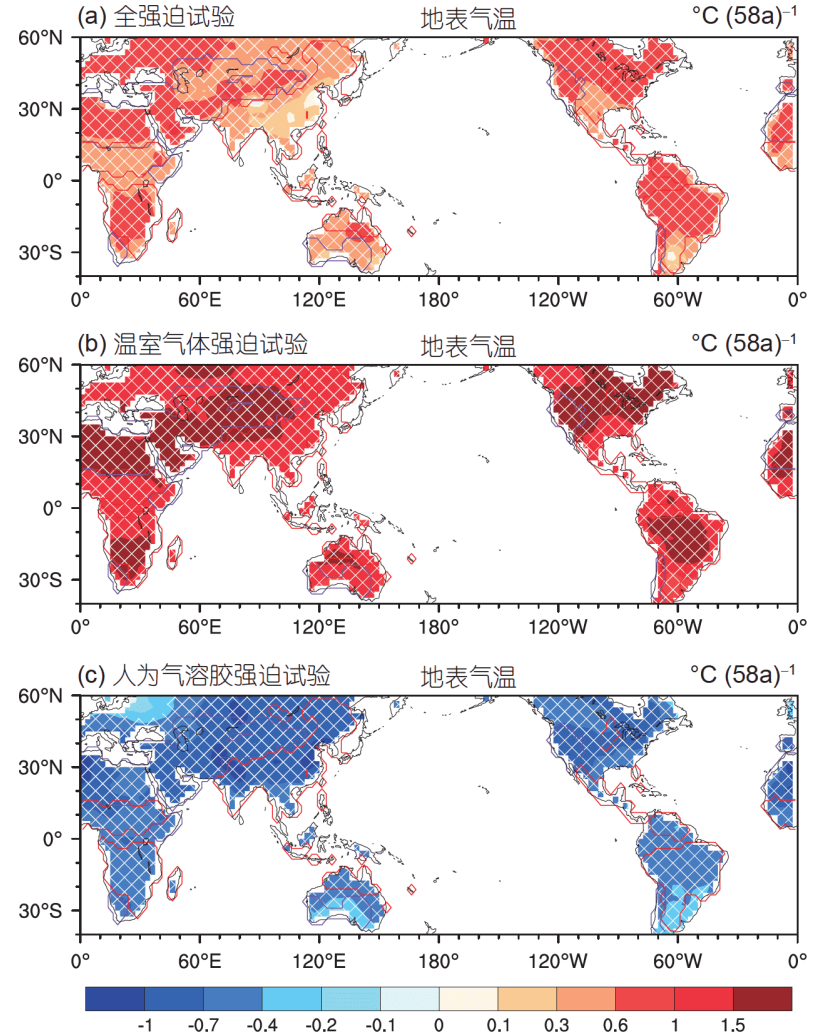

图 $101948 \sim 2005$ 年当地夏季地表温度线性趋势的水平 分布

(a) ALL-forcing多模式集合; (b) GHG-forcing多模式集合; (c) AAforcing多模式集合. 斜线区域通过了 $10 \%$ 显著性水平统计检验, 红色 实线为全球陆地季风区范围

需要指出的是，本文为研究不同外强迫因子对全 球季风降水的作用及其物理过程，采用了CMIP5全球 模式的集合模拟结果，其优点是通过多模式、多成员 集合来提高结果的可靠性. 需要指出的是，气溶胶的 气候效应非常复杂性, 既包括气溶胶的直接效应又包 括间接效应，涉及气溶胶-云相互作用过程，而当前气 候模式在对季风降水的模拟能力、对气溶胶气候效应 的物理过程处理方案等彼此间都存在差异，因此基于 模式估算的气溶胶气候效应结果尚存在较大不确定性 (吴国雄等, 2015; Li等, 2016; 周天军等, 2018). 有限的 气溶胶观测资料和云解析模式模拟表明，气溶胶对降 水的净影响(促进或抑制)依赖于气溶胶类型、气象背 景条件(如云水含量)、降水强度和区域等(Zhao等, 2006; Qian等, 2009; Li等, 2011). 基于卫星观测的气溶 胶和台站降水观测的研究表明, 近几十年来中国地区 气溶胶浓度的增加通过增加大气稳定度、减弱垂直运 
(a) 净地表向下辐射

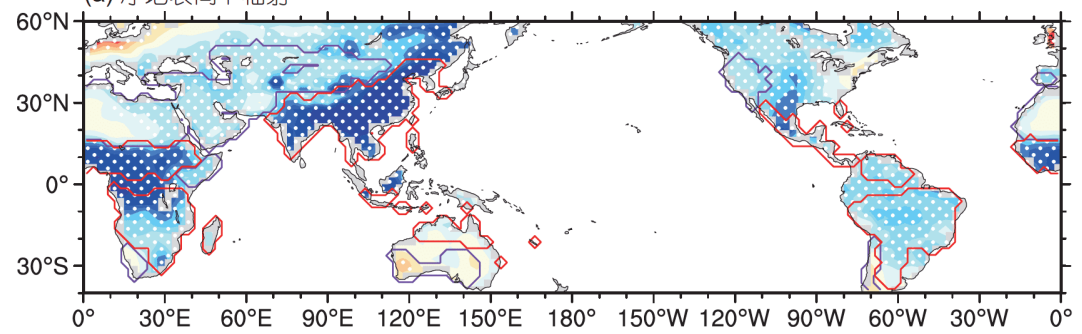

(b) 净地表向下短波辐射

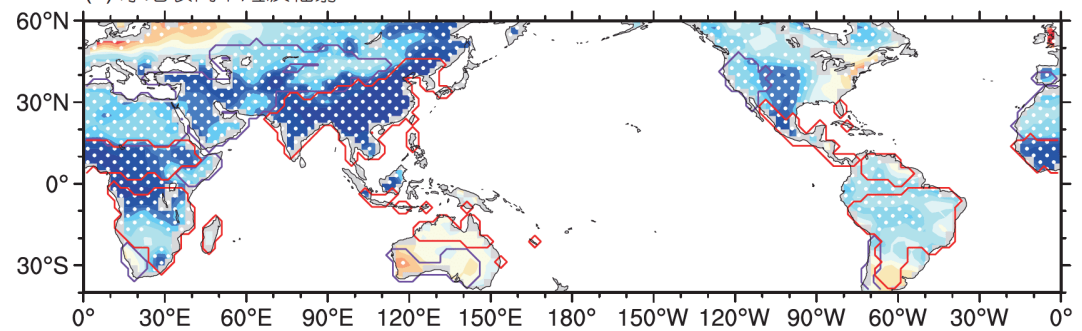

(c) 净地表向下长波辐射

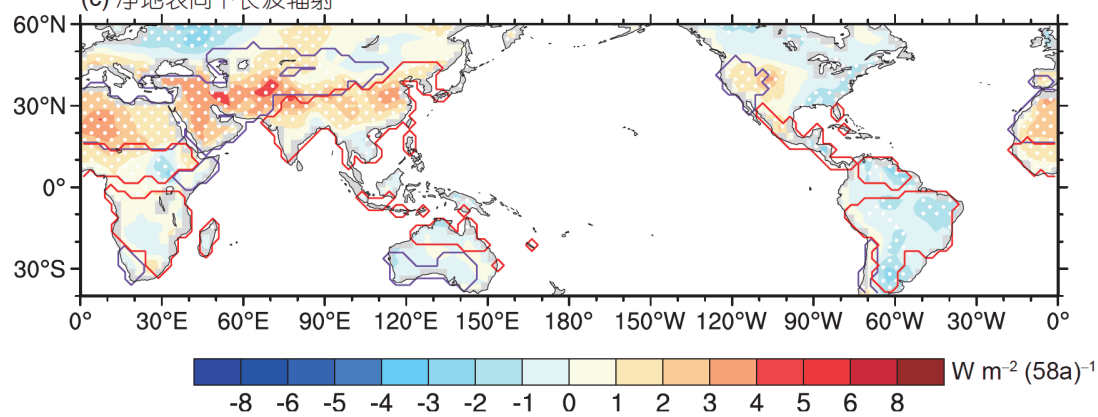

图 11 1948 2005年AA-forcing试验多模式集合平均模拟的当地夏季地表辐射通量的线性趋势分布

(a) 净地表向下辐射; (b) 净地表短波辐射; (c) 净地表长波辐射. 打点区域通过了 $10 \%$ 显著性水平统计检验, 红色实线为全球陆地季风区范围

动，使得中国中东部地区总降水减少(Zhao等，2006). 其中，气溶胶还可通过增加云滴数浓度、减小云滴大 小，从而影响到中国东部小雨的减少趋势(Qian等, 2009). 此外，观察资料中大气层顶的气溶胶辐射强迫 亦存在很大的不确定性，其 5 $95 \%$ 的不确定性范围为 $-1.9 \sim-0.1 \mathrm{~W} \mathrm{~m}{ }^{-2}$ (Myhre等, 2013), 因此驱动气候模式 进行历史气候模拟的气溶胶资料在不同季风区的质量 也存在不确定性，这也会影响到模拟结果及对相应物 理过程的理解，是造成检测归因结果不确定性范围较 大的原因之一. 特别是正在实施中的第六次耦合气候 模式比较计划(CMIP6，Eyring等，2016)更新了历史人 为气溶胶、温室气体及土地利用等人为强迫，用于驱 动最新的气候模式开展检测归因模式比较计划(DAMIP, Gillett等, 2016), 其结果将为季风区降水变化的检 测归因研究提供最新的数据支撑. 未来有待采用最新
的CMIP6模拟结果进一步揭示气溶胶影响全球季风降 水的机理. 注意CMIP多模式集合的框架仍包含模式结 构误差和参数化误差带来的不确定性. 如何基于观测 事实改进提升气候模式的性能、减小气候模式对于气 溶胶-气候影响过程描述的不确定性, 也是气溶胶和季 风相互作用领域的研究热点和挑战之一( $\mathrm{Li}$ 等, 2011; 吴国雄等, 2015; 周天军等, 2018).

\section{参考文献}

孙颖, 尹红, 田沁花, 胡婷, 石英, 刘洪滨, 周波涛. 2013. 全球和中国 区域近 50 年气候变化检测归因研究进展. 气候变化研究进展, 9: 235-245

吴国雄, 李占清, 符淙斌, 张小曳, 张人一, 张人禾, 周天军, 李建平, 李剑东, 周德刚, 武亮, 周连童, 何编, 黄荣辉. 2015. 气溶胶与东亚 季风相互影响的研究进展. 中国科学: 地球科学, 45: 1-19 
杨修群, 朱益民, 谢倩, 任雪娟, 徐桂玉. 2004. 太平洋年代际振荡的 研究进展. 大气科学, 28: 979-992

周天军, 吴波, 郭准, 何超, 邹立维, 陈晓龙, 张丽霞, 满文敏, 李普曦, 李东欢, 姚隽琛, 黄昕, 张文霞, 左萌, 陆静文, 孙宁. 2018. 东亚夏 季风变化机理的模拟和未来变化的预估：成绩和问题、机遇和 挑战. 大气科学, 42: 902-934

朱益民, 杨修群. 2003. 太平洋年代际振荡与中国气候变率的联系. 气象学报, 61: 641-654

Allen M R, Tett S F B. 1999. Checking for model consistency in optimal fingerprinting. Clim Dyn, 15: 419-434

Allen M R, Stott P A. 2003. Estimating signal amplitudes in optimal fingerprinting, Part I: Theory. Clim Dyn, 21: 477-491

Annamalai H, Hafner J, Sooraj K P, Pillai P. 2013. Global warming shifts the monsoon circulation, drying South Asia. J Clim, 26: 27012718

Beck C, Grieser J, Rudolf B. 2005. A new monthly precipitation climatology for the global land areas for the period 1951 to 2000 . DWD, Klimastatusbericht KSB 2004. 181-190

Bindoff N, Stott P, AchutaRao K, Allen M, Gillett N, Gutzler D, Hansingo K, Hegerl G, Hu Y, Jain S, Mokhov I, Overland J, Perlwitz J, Sebbari R, Zhang X. 2013. Detection and attribution of climate change: From global to regional. In: Stocker T F, Qin D, Plattner G K, Tignor M, Allen S K, Boschung J, Nauels A, Xia Y, Bex V, Midgley P M, eds. Climate Change 2013: The Physical Science Basis. Contribution of Working Group I to the Fifth Assessment Report of the Intergovernmental Panel on Climate Change. Cambridge: Cambridge University Press. 86

Bollasina M A, Ming Y, Ramaswamy V. 2011. Anthropogenic aerosols and the weakening of the South Asian summer monsoon. Science, 334: $502-505$

Chen M, Xie P, Janowiak J E, Arkin P A. 2002. Global land precipitation: A 50-yr monthly analysis based on gauge observations. J Hydrometeorol, 3: 249-266

Chen X, Zhou T. 2015. Distinct effects of global mean warming and regional sea surface warming pattern on projected uncertainty in the South Asian summer monsoon. Geophys Res Lett, 42: 9433-9439

Chou C, Wu T C, Tan P H. 2013a. Changes in gross moist stability in the tropics under global warming. Clim Dyn, 41: 2481-2496

Chou C, Chiang J C H, Lan C W, Chung C H, Liao Y C, Lee C J. 2013b. Increase in the range between wet and dry season precipitation. Nat Geosci, 6: 263-267

Dong B, Sutton R T, Highwood E J, Wilcox L J. 2016. Preferred response of the East Asian summer monsoon to local and non-local anthropogenic sulphur dioxide emissions. Clim Dyn, 46: 17331751

Eyring V, Bony S, Meehl G A, Senior C A, Stevens B, Stouffer R J,
Taylor K E. 2016. Overview of the coupled model intercomparison project phase 6 (CMIP6) experimental design and organization. Geosci Model Dev, 9: 1937-1958

Gillett N P, Shiogama H, Funke B, Hegerl G, Knutti R, Matthes K, Santer B D, Stone D, Tebaldi C. 2016. The detection and attribution model intercomparison project (DAMIP v1.0) contribution to CMIP6. Geosci Model Dev, 9: 3685-3697

Guo L, Highwood E J, Shaffrey L C, Turner A G. 2013. The effect of regional changes in anthropogenic aerosols on rainfall of the East Asian Summer Monsoon. Atmos Chem Phys, 13: 1521-1534

Harris I, Jones P D, Osborn T J, Lister D H. 2014. Updated highresolution grids of monthly climatic observations-the CRU TS3.10 Dataset. Int J Climatol, 34: 623-642

Held I M, Delworth T L, Lu J, Findell K L, Knutson T R. 2005. Simulation of Sahel drought in the 20th and 21st centuries. Proc Natl Acad Sci USA, 102: 17891-17896

Held I M, Soden B J. 2006. Robust responses of the hydrological cycle to global warming. J Clim, 19: 5686-5699

Hegerl G, Hoegh-Guldberg O, Casassa G, Hoerling M, Kvats S, Parmesan C, Pierce D, Stott P. 2010. Good practice guidance paper on detection and attribution related to anthropogenic climate change. In: Stocker T F, Field C B, Qin D, Barros V, Plattner G K, Tignor M, Midgley P M, Ebi K L, eds. Meeting Report of the Intergovernmental Panel on Climate Change Expert Meeting on Detection and Attribution of Anthropogenic Climate Change. IPCC Working Group I Technical Support Unit. University of Bern, Bern, Switzerland. 8

Huang X, Zhou T, Turner A, Dai A, Chen X, Clark R, Jiang J, Man W, Murphy J, Rostron J, Wu B, Zhang L, Zhang W, Zou L. 2020. The Recent decline and recovery of Indian summer monsoon rainfall: Relative roles of external forcing and internal variability. J Clim, doi: 10.1175/JCLI-D-19-0833.1

Jiang J, Zhou T. 2019. Global monsoon responses to decadal sea surface temperature variations during the twentieth century: Evidence from AGCM simulations. J Clim, 32: 7675-7695

Jiang Y, Liu X, Yang X Q, Wang M. 2013. A numerical study of the effect of different aerosol types on East Asian summer clouds and precipitation. Atmos Environ, 70: 51-63

Jiang Y, Yang X Q, Liu X. 2015. Seasonality in anthropogenic aerosol effects on East Asian climate simulated with CAM5. J Geophys Res-Atmos, 120: 10837-10861

Kitoh A, Endo H, Krishna Kumar K, Cavalcanti I F A, Goswami P, Zhou T. 2013. Monsoons in a changing world: A regional perspective in a global context. J Geophys Res-Atmos, 118: 3053-3065

Krishnan R, Sabin T P, Vellore R, Mujumdar M, Sanjay J, Goswami B 
N, Hourdin F, Dufresne J L, Terray P. 2016. Deciphering the desiccation trend of the South Asian monsoon hydroclimate in a warming world. Clim Dyn, 47: 1007-1027

Krishnamurthy L, Krishnamurthy V. 2014. Influence of PDO on South Asian summer monsoon and monsoon-ENSO relation. Clim Dyn, 42: $2397-2410$

Lamarque J F, Bond T C, Eyring V, Granier C, Heil A, Klimont Z, Lee D, Liousse C, Mieville A, Owen B, Schultz M G, Shindell D, Smith S J, Stehfest E, Van Aardenne J, Cooper O R, Kainuma M, Mahowald N, McConnell J R, Naik V, Riahi K, van Vuuren D P. 2010. Historical (1850-2000) gridded anthropogenic and biomass burning emissions of reactive gases and aerosols: Methodology and application. Atmos Chem Phys, 10: 7017-7039

Lau K M, Kim M K, Kim K M. 2006. Asian summer monsoon anomalies induced by aerosol direct forcing: The role of the Tibetan Plateau. Clim Dyn, 26: 855-864

Lau W K M, Kim K M. 2017. Competing influences of greenhouse warming and aerosols on Asian summer monsoon circulation and rainfall. Asia-Pac J Atmos Sci, 53: 181-194

Li H, Dai A, Zhou T, Lu J. 2010. Responses of East Asian summer monsoon to historical SST and atmospheric forcing during 19502000. Clim Dyn, 34: 501-514

Li M, Liu H, Geng G, Hong C, Liu F, Song Y, Tong D, Zheng B, Cui H, Man H, Zhang Q, He K. 2017. Anthropogenic emission inventories in China: A review. Natl Sci Rev, 4: 834-866

Li Z, Lau W K, Ramanathan V, Wu G, Ding Y, Manoj M G, Liu J, Qian Y, Li J, Zhou T, Fan J, Rosenfeld D, Ming Y, Wang Y, Huang J, Wang B, Xu X, Lee S, Cribb M, Zhang F, Yang X, Zhao C, Takemura T, Wang K, Xia X, Yin Y, Zhang H, Guo J, Zhai P M, Sugimoto N, Babu S S, Brasseur G P. 2016. Aerosol and monsoon climate interactions over Asia. Rev Geophys, 54: 866-929

Li Z, Li C, Chen H, Tsay S C, Holben B, Huang J, Li B, Maring H, Qian Y, Shi G, Xia X, Yin Y, Zheng Y, Zhuang G. 2011. East Asian studies of tropospheric aerosols and their impact on regional climate (EAST-AIRC): An overview. J Geophys Res, 116: D00K34

Liepert B G, Lo F. 2013. CMIP5 update of "Inter-model variability and biases of the global water cycle in CMIP3 coupled climate model". Environ Res Lett, 8: 029401

Lin R, Zhou T, Qian Y. 2014. Evaluation of global monsoon precipitation changes based on five reanalysis datasets. J Clim, 27: $1271-1289$

Meehl G A, Arblaster J M, Collins W D. 2008. Effects of black carbon aerosols on the Indian monsoon. J Clim, 21: 2869-2882

Ma S, Zhou T, Stone D A, Polson D, Dai A, Stott P A, von Storch H, Qian Y, Burke C, Wu P, Zou L, Ciavarella A. 2017. Detectable anthropogenic shift toward heavy precipitation over eastern China. J
Clim, 30: 1381-1396

Myhre G, Shindell D, Bréon F M, Collins W, Fuglestvedt J, Huang J. 2013. Anthropogenic and natural radiative forcing. In: Climate Change 2013: The Physical Science Basis. Contribution of Working Group I to the Fifth Assessment Report of the Intergovernmental Panel on Climate Change. Cambridge: Cambridge University Press

Pascale S, Boos W R, Bordoni S, Delworth T L, Kapnick S B, Murakami H, Vecchi G A, Zhang W. 2017. Weakening of the North American monsoon with global warming. Nat Clim Change, 7: 806812

Paul S, Ghosh S, Oglesby R, Pathak A, Chandrasekharan A, Ramsankaran R. 2016. Weakening of Indian summer monsoon rainfall due to changes in land use land cover. Sci Rep, 6: 32177

Peterson T C, Vose R S. 1997. An overview of the global historical climatology network temperature database. Bull Amer Meteorol Soc, 78: 2837-2849

Polson D, Bollasina M, Hegerl G C, Wilcox L J. 2014. Decreased monsoon precipitation in the Northern Hemisphere due to anthropogenic aerosols. Geophys Res Lett, 41: 6023-6029

Rotstayn L D, Jeffrey S J, Collier M A, Dravitzki S M, Hirst A C, Syktus J I, Wong K K. 2012. Aerosol- and greenhouse gas-induced changes in summer rainfall and circulation in the Australasian region: A study using single-forcing climate simulations. Atmos Chem Phys, 12: 6377-6404

Salzmann M, Weser H, Cherian R. 2014. Robust response of Asian summer monsoon to anthropogenic aerosols in CMIP5 models. J Geophys Res-Atmos, 119: 11321-11337

Qian Y, Flanner M G, Leung L R, Wang W. 2011. Sensitivity studies on the impacts of Tibetan Plateau snowpack pollution on the Asian hydrological cycle and monsoon climate. Atmos Chem Phys, 11: 1929-1948

Qian Y, Gong D, Fan J, Leung L R, Bennartz R, Chen D, Wang W. 2009. Heavy pollution suppresses light rain in China: Observations and modeling. J Geophys Res, 114: D00K02

Sato M, Hansen J E, McCormick M P, Pollack J B. 1993. Stratospheric aerosol optical depths, 1850-1990. J Geophys Res, 98: 2298722994

Schneider T, O'Gorman P A, Levine X J. 2010. Water vapor and the dynamics of climate changes. Rev Geophys, 48: RG3001

Schneider U, Becker A, Finger P, Meyer-Christoffer A, Ziese M, Rudolf B. 2014. GPCC's new land surface precipitation climatology based on quality-controlled in situ data and its role in quantifying the global water cycle. Theor Appl Climatol, 115: 15-40

Song F, Zhou T, Qian Y. 2014. Responses of East Asian summer monsoon to natural and anthropogenic forcings in the 17 latest 
CMIP5 models. Geophys Res Lett, 41: 596-603

Sun Y, Zhang X, Zwiers F W, Song L, Wan H, Hu T, Yin H, Ren G. 2014. Rapid increase in the risk of extreme summer heat in Eastern China. Nat Clim Change, 4: 1082-1085

Taylor K E, Stouffer R J, Meehl G A. 2012. An overview of CMIP5 and the experiment design. Bull Amer Meteorol Soc, 93: 485-498

Wang B, Ding Q. 2006. Changes in global monsoon precipitation over the past 56 years. Geophys Res Lett, 33: L06711

Wang B, Ding Q. 2008. Global monsoon: Dominant mode of annual variation in the tropics. Dyn Atmos Oceans, 44: 165-183

Wang B, Liu J, Kim H J, Webster P J, Yim S Y. 2012. Recent change of the global monsoon precipitation (1979-2008). Clim Dyn, 39: $1123-1135$

Wang B, Liu J, Kim H J, Webster P J, Yim S Y, Xiang B. 2013. Northern Hemisphere summer monsoon intensified by mega-El Nino/southern oscillation and Atlantic multidecadal oscillation. Proc Natl Acad Sci USA, 110: 5347-5352

Wang Z, Lin L, Yang M, Xu Y, Li J. 2017. Disentangling fast and slow responses of the East Asian summer monsoon to reflecting and absorbing aerosol forcings. Atmos Chem Phys, 17: 11075-11088

Willmott C, Matsuura K. 2001. Terrestrial air temperature and precipitation: Monthly and annual time series (1950-1996). http:// climate.geog.udel.edu/ climate/html_pages/README.ghcn_ts. html
Wu P, Christidis N, Stott P. 2013. Anthropogenic impact on Earth's hydrological cycle. Nat Clim Change, 3: 807-810

Xu Y, Gao X, Shi Y, Botao Z. 2015. Detection and attribution analysis of annual mean temperature changes in China. Clim Res, 63: 61-71

Zhang L, Zhou T. 2011. An assessment of monsoon precipitation changes during 1901-2001. Clim Dyn, 37: 279-296

Zhang L, Zhou T. 2014. An assessment of improvements in global monsoon precipitation simulation in FGOALS-s2. Adv Atmos Sci, 31: $165-178$

Zhang W, Zhou T, Zou L, Zhang L, Chen X. 2018. Reduced exposure to extreme precipitation from $0.5^{\circ} \mathrm{C}$ less warming in global land monsoon regions. Nat Commun, 9: 3153

Zhang X, Zwiers F W, Hegerl G C, Lambert F H, Gillett N P, Solomon S, Stott P A, Nozawa T. 2007. Detection of human influence on twentieth-century precipitation trends. Nature, 448: 461-465

Zhao C, Tie X, Lin Y. 2006. A possible positive feedback of reduction of precipitation and increase in aerosols over eastern central China. Geophys Res Lett, 33: L11814

Zhou T, Zhang L, Li H. 2008a. Changes in global land monsoon area and total rainfall accumulation over the last half century. Geophys Res Lett, 35: L16707

Zhou T, Yu R, Li H, Wang B. 2008b. Ocean forcing to changes in global monsoon precipitation over the recent half-century. J Clim, 21: $3833-3852$

(责任编委: 黄建平) 